\title{
Colaborar ou cooperar? diz espelho meu!
}

\author{
Gerson Ribeiro Bacury \\ Universidade Federal do Amazonas (Brasil) \\ Maria Salonilde Ferreira \\ Universidade Federal do Rio Grande do Norte (Brasil)
}

\section{Resumo}

Este artigo discute as reflexões relativas às interfaces colaborar/cooperar em processos formativos mediados por práticas investigativas em Educação da Matemática, com destaque à abordagem colaborativa crítico-reflexiva. A indagação que se coloca é a de explicitar as relações que se estabelecem entre elas, considerando as peculiaridades inerentes à colaboração e à cooperação. Nesse sentido, o texto enfatiza, inicialmente, os aspectos distintivos entre esses dois conceitos como parâmetro de análise e compreensão das relações prováveis que se estabelecem entre ambos, considerando os resultados de estudos e pesquisas de autores que refletem sobre essa temática e os fundamentos da teoria do discurso (BAKHTIN, 2003). Buscamos, em seguida, elementos empíricos possíveis de tornar evidentes essas relações e conexões a partir de um contexto que privilegia a pesquisa como eixo central do processo formativo. E, por fim, destacamos a complexidade desses processos e a necessidade de compreender e considerar a pluralidade de procedimentos metodológicos que eles requerem.

Palavras-chave: Pesquisa. Formação. Cooperação. Colaboração.

\section{To collaborate or to cooperate? mirror says myself!}

\section{Abstract}

This article discusses the reflections related to the to collaborate / to cooperate interfaces in formative processes mediated by investigative practices in Mathematics Education, with emphasis on the reflective critical collaborative approach. The question that arises is to explain the relationships that are established between them, considering the peculiarities inherent in collaboration and cooperation. In this sense, the text, initially, emphasizes the distinctive aspects between these two concepts as a parameter of analysis and understanding of the probable relationships that are established between both, considering the results of studies and research by authors that reflect on this theme and the foundations of theory of the speech (BAKHTIN, 2003). We then seek empirical elements that can make evident these relationships and connections from a context that privileges research as the central axis of the formative process. And, finally, we highlight the complexity of these processes and the need to understand and consider the plurality of methodological procedures that they require.

Keywords: Research. Formation. Cooperation. Collaboration. 
Colaborar ou cooperar? diz espelho meu!

\section{¿Colaborar o cooperar? dice mi espejo!}

\section{Resumen}

Este artículo discute las reflexiones relativas a las interfaces colaborar / cooperar en procesos formativos mediados por prácticas de investigación en Educación Matemática, con destaque en el enfoque colaborativo crítico-reflexivo. La pregunta que surge es explicar las relaciones establecidas entre ellos, considerando las peculiaridades inherentes a la colaboración y la cooperación. En este sentido, el texto enfatiza, inicialmente, los aspectos distintivos entre estos dos conceptos como parámetro de análisis y comprensión de las relaciones probables que se establecen entre ambas, considerando los resultados de estudios e investigaciones de autores que reflexionan sobre esa temática y los fundamentos de la teoría del discurso (BAKHTIN, 2003). Luego, buscamos, busca elementos empíricos posibles de hacer evidentes esas relaciones y conexiones a partir de un contexto que privilegia la investigación con eje central del proceso formativo. Y, finalmente, destacamos la complejidad de estos procesos y la necesidad de comprender y considerar la pluralidad de procesos procedimientos metodológicos que requieren. Palabras clave: Investigación. Formación. Cooperación. Colaboración.

O que é que a ciência tem? Tem lápis de calcular, Que é mais que a ciência tem? Borracha pra depois apagar.

Você já foi ao espelho, nêgo? Não? Então vá!

(RAUL SEIXAS, 1978)

O desafio lançado por Raul Seixas nos fez ir ao espelho para revermos a face do que está posto em relação à oposição presente no contexto das pesquisas em Educação - cooperar ou colaborar. Para tanto, recorreremos, inicialmente, ao que está posto, em seguida buscaremos desvendar suas interconexões e refletir sobre a função que essas atividades desempenham nos processos formativos mediados pela abordagem colaborativa crítico-reflexiva.

\section{O que o espelho revela}

A colaboração e a cooperação são dois fenômenos que vêm sendo objeto de reflexão em diversas áreas do conhecimento. Podemos destacar, entre outras, a Linguística, a Educação e a Educação Matemática.

Do ponto de vista etimológico colaborar e cooperar se originam do latim collaborare e cooperare, respectivamente, e têm o mesmo significado ajudar, auxiliar. No entanto, a partir das abordagens de pesquisa qualitativas, em particular a pesquisa colaborativa, iniciou-se uma discussão no sentido de 
estabelecer suas especificidades, em virtude dessa modalidade de pesquisa instituir o conceito de colaboração como eixo de sustentação epistemológica.

Desse modo, autores como Boavida e Ponte (2002), Ibiapina (2009) e Magalhães (2009; 2004), entre outros, buscam distingui-las, evidenciando suas diferenças, no sentido de, explicitar suas especificidades.

Boavida e Ponte (2002) destacam que os conceitos: cooperar e colaborar, embora tenha o mesmo prefixo "co", cujo significado é ação conjunta, diferem significativamente. Cooperar significa em latim operare loperar, executar, fazer, realizar); colaborar, labore (trabalhar, produzir, exercer uma atividade com um fim previsto). Se, do ponto de vista etimológico, seus significados se diferenciam, essa diferenciação se acentua ainda mais no que se refere ao aspecto conceitual. Para esses autores, na cooperação ocorre a simples realização conjunta de diversas operações. A colaboração, no entanto, vai um pouco além, requer maior partilha e interação por parte de seus membros.

Autores como Magalhães (2002; 2004; 2009), Celani (2003), Ibiapina (2009), Ibiapina e Magalhães (2012) e Ferreira (2012), ente outros, evidenciam que diferentemente da cooperação, a colaboração implica tomada de decisões democráticas, ação comum e comunicação entre os partícipes na consecução de determinados fins. Para Celani:

[... ] o conceito de colaboração é definido pela igualdade de oportunidades dos partícipes da interação em colocar em discussão sentidos/significados, valor e conceitos suas ações, escolhas, dúvidas e discordâncias [...] e que colaborar exige [...] trabalho ativo, consciente que pressupõe esforço, vontade e que tem lugar quando as condições são criadas para isso (CELANI, 2003, p. 23).

Entretanto, Magalhães adverte:

Colaborar, em qualquer contexto (pesquisa, formação contínua, sala de aula), significa agir no sentido de possibilitar que os agentes participantes tornem seus processos mentais claros, expliquem, demonstrem, com o objetivo de criar, para os outros participantes, possibilidades de questionar, expandir, recolocar o que foi posto em negociação (MAGALHÃES, 2004, p. 76).

Por outro lado, Ibiapina (2009, p. 215), tomando como parâmetro o conceito de zona proximal de desenvolvimento, elaborado por Vigotski, 
assinala que "[...] colaboração significa a ajuda que um par mais experiente dá a outro menos experiente no momento da realização de determinada atividade".

Já Ferreira (2012, p. 366) ressalta que a colaboração busca especificar seu significado, conceituando-a como "[...] uma ação compartilhada entre sujeitos com interesses comuns, pautada pelo diálogo e pela negociação". E acrescenta que a colaboração

[...] requer implicar-se de forma volitiva e consciente, estabelecer relações mais igualitárias e democráticas, tendo cada um dos participantes vez e voz, poder de decisão sobre as ações efetivadas conjuntamente e autonomia (FERREIRA, 2012, p. 366).

Pelo exposto, podemos constatar que colaborar e cooperar apresentam semelhanças, mas particularmente diferenças significativas, constituindo-se a colaboração uma atividade complexa que adquire uma expansão mais ampliada no contexto da pesquisa colaborativa à medida que exige uma atuação crítica do sujeito.

Nessa perspectiva, Oliveira argumenta que:

[...] colaborar criticamente significa compromisso com necessidades do contexto particular de ação dos participantes, com base em um diálogo que objetiva esclarecer e despertar a consciência de cada um para compreender as questões sócio-histórico-culturais que os/as rodeiam, a realidade em que vivem (OLIVEIRA, 2011 , p. 721.

Autores como John-Steiner (2000), Magalhães (2008; 2009; 2009a), Ferreira e Ibiapina (201 1) e Ibiapina e Magalhães (2012), entre outros, elencam algumas condições favoráveis à emergência da colaboração crítica, tais como:

- Oportunidades para a produção de conhecimentos em dialógica interativa, de modo que os participantes expressem suas ideias e significados;

- Incentivo à participação no diálogo, estimulando todos a ouvir e serem ouvidos de forma a promover o compartilhamento discursivo; 
- Negociação e compartilhamento onde haja possibilidades iguais de questionar, discordar e solicitar esclarecimentos sem se sentir ameaçado, nem coagido;

- Uso de argumentos discursivos passíveis de tornar os temas em debate significativos para todos;

- Análise e interpretação de práticas e teorias, a fim de superar suas inadequações;

- Respeito ao direito que cada um tem de pôr em discussão seus valores, crenças, princípios, concepções, ideias e conceitos;

- Predominância da explicitação, da partilha e da negociação das contradições que emergem nas interações;

- Ampliação das condições de pensar e agir de forma consciente e voluntária;

- Efetivação de ações que contribuam para a superação de situações econômicas, políticas e sociais adversas, presentes nos contextos em que atuam;

- Mobilização de recursos que possibilitem a emancipação dos participantes e os tornem mais críticos e questionadores;

- Produção de meios em que as contradições e conflitos impulsionem o aprendizado e o desenvolvimento mútuo;

- Atenção ao sentido histórico da realidade, valorizando o passado e o presente e suas conexões com o vir a ser;

- Desenvolvimento das potencialidades individuais;

- Compreensão da unidade cognição/afetividade.

Considerando as peculiaridades inerentes à colaboração e à cooperação, a questão que se coloca é de explicitar as relações que se estabelecem entre os conceitos em processos investigativos que interconectam pesquisa e formação.

Nessa direção, organizamos o artigo em três partes. Na primeira, enfatizamos a distinção entre cooperação e colaboração como parâmetro de análise e compreensão das relações prováveis de se estabelecerem entre ambas, em processos formativos mediados pela pesquisa. Na segunda parte, buscamos elementos possíveis de tornar evidentes essas relações e conexões. E, na terceira parte, destacamos a complexidade dos processos formativos e a necessidade de compreender e considerar a pluralidade de procedimentos 
metodológicos que esses processos requerem, particularmente, quando mediados pela inter-relação pesquisa/formação.

\section{O espelho revela tudo?}

A proposição da colaboração como componente de processos formativos crítico-reflexivo de professores, seja formação inicial ou contínua, vem se tornando objeto, cada vez mais frequente, de estudos e análises.

No entanto, é preciso estudar as conexões que eclodem no desenrolar desses processos para que se tornem viáveis as intenções de se formar professores com o perfil que se tornou desejável - o professor crítico-reflexivo, pesquisador de sua prática.

Nesse sentido, como anunciamos anteriormente, consideramos como objeto de análise a relação entre colaboração e cooperação. Para efetivar o que nos propomos, tornou-se necessário buscar elementos numa abordagem investigativa que privilegiasse a pesquisa como elemento central da formação

6 profissional do professor.

Dentre as inúmeras possibilidades nos decidimos em recolher elementos empíricos que dessem sustentação às nossas análises nos dados resultantes da pesquisa intitulada "Práticas Investigativas na formação de futuros professores de Matemática", objetivando contribuir para a formação de futuros professores de Matemática, mediado por práticas investigativas, com base na abordagem colaborativa crítico-reflexiva, conforme Bacury (2017).

\section{O contexto da pesquisa}

AsA investigação de referência teve como arcabouço metodológico a abordagem colaborativa crítico-reflexiva proposta por Ferreira (2012) e por Ibiapina (2008) e o universo empírico foi constituido por estudantes matriculados nas disciplinas de Estágio Supervisionado I e II, no período letivo de 2016/2 até 2017/1, no curso de Licenciatura em Matemática da Universidade Federal do Amazonas (UFA campus Manaus.

Para compor o grupo de partícipes da referida pesquisa, foram estabelecidos os seguintes critérios: 
- Estar regularmente matriculado na disciplina de Estágio Supervisionado I;

- Ter interesse em participar nas atividades do Grupo de Estudos e Pesquisas de Práticas Investigativas em Educação Matemática (GEPIMat) de forma voluntária e consciente;

- Afiliação voluntária no GEPIMat.

Os dois últimos critérios se fundamentaram num dos princípios da pesquisa colaborativa em que a participação tem que ser uma decisão volitiva e consciente. Desse modo, foi realizada uma reunião com a finalidade de esclarecer os objetivos da proposta de formação e a assinatura dos termos de livre esclarecimento, de utilização de imagem e de utilização das falas. Foi definido que os participantes seriam identificados pelo sobrenome de cada um.

As especificidades que o estudo assumiu (formação inicial centrada na pesquisa colaborativa, no contexto de uma disciplina curricular) induziram o proponente a criar um espaço que propiciasse vivências que se coadunassem com os propósitos da abordagem colaborativa adotada, isto é, a colaboração, a reflexão e a produção de conhecimentos. Assim, foi constituído o GEPIMat.

\section{O GEPIMat}

Grupo de Estudos e Pesquisas de Práticas Investigativas em Educação Matemática (GEPIMat) foi institucionalizado e registrado por meio da solicitação do Termo de Anuência junto à Pró-reitoria de Pesquisa e Pósgraduação (Propesp)/UFAM. O GEPIMat iniciou suas atividades em 03 de junho de 2016 '.

Compuseram o grupo: o coordenador da pesquisa, o professor coordenador da disciplina de Estágio Supervisionado, dois professores pesquisadores da UFAM/campus de Coari e os 11 estudantes regularmente matriculados nas disciplinas de Estágio Supervisionado.

As atividades do grupo se efetivaram nos dias destinados às aulas das disciplinas Estágio Supervisionado I e II no período matutino das 8 h às $12 \mathrm{~h}$, às sextas-feiras, segundo o planejamento a seguir, apresentado nos quadros 1 e 2. 
Quadro 1

Atividades desenvolvidas no GEPIMat - Estágio Supervisionado I

\begin{tabular}{|c|c|l|}
\hline Encontro & Data & \multicolumn{1}{|c|}{ Atividade (s) desenvolvida (s) } \\
\hline 01 & $03 / 06 / 2016$ & $\begin{array}{l}\text { Apresentação da disciplina (plano, metodologia, ava- } \\
\text { liação, entre outros); apresentação do pesquisador e } \\
\text { exerć́cio verbal para construir os percursos formativos. }\end{array}$ \\
\hline 02 & $10 / 06 / 2016$ & $\begin{array}{l}\text { Apresentação da pesquisa aos partícipes e recolhimento } \\
\text { da primeira versão dos percursos formativos. }\end{array}$ \\
\hline 03 & $17 / 06 / 2016$ & $\begin{array}{l}\text { Continuação da apresentação da pesquisa aos partícipes } \\
\text { e elaboração de como realizar uma síntese. }\end{array}$ \\
\hline 04 & $24 / 06 / 2016$ & $\begin{array}{l}\text { Discussão do primeiro texto: "A dimensão do conhecimen- } \\
\text { to: a busca de um novo paradigma" (GRECO, 1994) }\end{array}$ \\
\hline 05 & $01 / 07 / 2016$ & Oficina pedagógica: "Como construir uma síntese?" \\
\hline 07 & $15 / 07 / 2016$ & $\begin{array}{l}\text { Palestra do Prof. Me. Ademar Vieira sobre a temáti- } \\
\text { ca: "Experiências e vivências como doutorando, na } \\
\text { Universidade de Aveiro - Portugal" }\end{array}$ \\
\hline 08 & $22 / 07 / 2016$ & $\begin{array}{l}\text { Atividade Matemática com o Prof. Me. Domingos } \\
\text { Anselmo. }\end{array}$ \\
\hline 09 & $29 / 07 / 2016$ & $\begin{array}{l}\text { Palestra do Prof. Me. Jorge Menezes Rodrigues sobre a } \\
\text { temática: "AMatemática es portadores de necessidades } \\
\text { educacionais especiais". }\end{array}$ \\
\hline 10 & $05 / 08 / 2016$ & $\begin{array}{l}\text { Planejamento para apresentação dos colaboradores } \\
\text { às escolas parceiras pelo par mais experiente e pelos } \\
\text { partícipes. }\end{array}$ \\
\hline 13 & $26 / 08 / 2016$ & $\begin{array}{l}\text { Palestra do Prof. Me. Domingos Anselmo sobre a te- } \\
\text { mática: "A relação entre a Matemática acadêmica e a } \\
\text { Matemática escolar nas práticas docentes da Educação } \\
\text { Básica". }\end{array}$ \\
\hline \begin{tabular}{l} 
Atividade com o Prof. Me. Domingos Anselmo. \\
\hline 11
\end{tabular} $12 / 08 / 2016$ & $\begin{array}{l}\text { Orientações aos partícipes sobre o que observar nas es- } \\
\text { colas e seus os principais aspectos por parte do par mais } \\
\text { experiente. }\end{array}$ \\
\hline $19 / 08 / 201$
\end{tabular}




\section{Quadro 1}

Atividades desenvolvidas no GEPIMat - Estágio Supervisionado I (continuação)

\begin{tabular}{|c|c|l|}
\hline Encontro & Data & \multicolumn{1}{c|}{ Atividade (s) desenvolvida (s) } \\
\hline 14 & $02 / 09 / 2016$ & $\begin{array}{l}\text { Apresentação das escolas parceiras e suas características, } \\
\text { pelos partícipes. }\end{array}$ \\
\hline 15 & $09 / 09 / 2016$ & $\begin{array}{l}\text { Apresentação das escolas parceiras e suas características, } \\
\text { pelos partícipes. }\end{array}$ \\
\hline 16 & $16 / 09 / 2016$ & $\begin{array}{l}\text { Encerramento da Disciplina de Estágio Supervisionado I. } \\
\text { Considerações sobre a primeira fase da empiria. }\end{array}$ \\
\hline
\end{tabular}

Fonte: Bacury (2017).

Quadro 2

Atividades desenvolvidas no GEPIMat - Estágio Supervisionado II

\begin{tabular}{|c|c|l|}
\hline Encontro & Data & \multicolumn{1}{|c|}{ Atividade (s) desenvolvida (s) } \\
\hline 01 & $28 / 10 / 2016$ & $\begin{array}{l}\text { Socialização das ações que serão desenvolvidas no } \\
\text { período de 2016/2, durante a realização do Estágio } \\
\text { Supervisionado Il pelo par mais experiente. }\end{array}$ \\
\hline 02 & $04 / 11 / 2016$ & $\begin{array}{l}\text { Apresentação da pesquisa aos partícipes e recolhimento } \\
\text { da primeira versão dos percursos formativos. }\end{array}$ \\
\hline 02 & $04 / 11 / 2016$ & $\begin{array}{l}\text { Apresentação das escolas parceiras e suas características } \\
\text { pelos partícipes. }\end{array}$ \\
\hline 03 & $18 / 11 / 2016$ & $\begin{array}{l}\text { Sessão reflexiva: socialização dos percursos formativos } \\
\text { pelos partícipes. }\end{array}$ \\
\hline 04 & $25 / 11 / 2016$ & $\begin{array}{l}\text { Discussão do terceiro texto: "Professor-investigador: } \\
\text { Que sentido? Que formação? (ALARCÃO, 200 1 pelos } \\
\text { partícipes. }\end{array}$ \\
\hline 05 & $02 / 12 / 2016$ & $\begin{array}{l}\text { Discussão do quarto texto: "A abordagem colaborativa: } \\
\text { uma articulação entre pesquisa e formação " (FERREIRA, } \\
\text { 20 12) pelos partícipes. }\end{array}$ \\
\hline 06 & $09 / 12 / 2016$ & $\begin{array}{l}\text { Construção das sínteses dos textos de Alarcão (200 1) e } \\
\text { Ferreira (2012) pelos partícipes. }\end{array}$ \\
\hline 07 & $10 / 12 / 2016$ & $\begin{array}{l}\text { Construção das sínteses do texto de Alarcão (200 1) e } \\
\text { Ferreira (2012) pelos partícipes. }\end{array}$ \\
\hline
\end{tabular}


Quadro 2

Atividades desenvolvidas no GEPIMat - Estágio Supervisionado II (continuação)

\begin{tabular}{|c|c|c|}
\hline Encontro & Data & Atividade (s) desenvolvida (s) \\
\hline 08 & $16 / 12 / 2016$ & $\begin{array}{l}\text { Encerramento do ano de } 2016 \text {, devido ao recesso natalino Sessão } \\
\text { reflexiva: produções textuais. }\end{array}$ \\
\hline 09 & $06 / 01 / 2017$ & $\begin{array}{l}\text { Palestra da Prof. a Dra. Elisângela Melo sobre a temática: "Formação } \\
\text { de Professores de Matemática na perspectiva da Etnomatemática e } \\
\text { Comunidades de Prática". }\end{array}$ \\
\hline 10 & $11 / 01 / 2017$ & $\begin{array}{l}\text { Primeiro atendimento às equipes para a elaboração dos projetos } \\
\text { de ensino de Matemática e Instrumento Didático pelo par mais } \\
\text { experiente. }\end{array}$ \\
\hline 11 & $13 / 01 / 2017$ & $\begin{array}{l}\text { Apresentação prévia dos projetos de ensino de Matemática pelos } \\
\text { partícipes. }\end{array}$ \\
\hline 12 & $18 / 01 / 2017$ & $\begin{array}{l}\text { Segundo atendimento às equipes para a elaboração dos projetos } \\
\text { de ensino de Matemática e Instrumento Didático pelo par mais } \\
\text { experiente. }\end{array}$ \\
\hline 12 & 20/01/2017 & $\begin{array}{l}\text { Aula simulada I e Aula simulada II, subsidiadas pelas práticas } \\
\text { elaboradas nos projetos de ensino de Matemática e Instrumento } \\
\text { Didático pelos partícipes. }\end{array}$ \\
\hline 13 & $25 / 01 / 2017$ & Terceiro atendimento às equipes pelo par mais experiente. \\
\hline 14 & $27 / 01 / 2017$ & $\begin{array}{l}\text { Aula simulada III Aula simulada IV, subsidiada pelas práticas elabo- } \\
\text { radas nos projetos de ensino de Matemática e Instrumento Didático } \\
\text { pelos partícipes. }\end{array}$ \\
\hline 15 & $01 / 02 / 2017$ & Quarto atendimento à equipe pelo par mais experiente. \\
\hline 16 & $01 / 02 / 2017$ & $\begin{array}{l}\text { Aula simulada V, subsidiada pelas práticas elaboradas nos projetos } \\
\text { de ensino de Matemática e Instrumento Didática pelos partícipes. }\end{array}$ \\
\hline 17 & $10 / 02 / 2017$ & $\begin{array}{l}\text { Orientação às equipes quanto às sugestões e reformulações para } \\
\text { o projeto de Ensino de Matemática e Instrumento Didático pelo par } \\
\text { mais experiente. }\end{array}$ \\
\hline 18 & $17 / 02 / 2017$ & $\begin{array}{l}\text { Orientação às equipes quanto às sugestões e reformulações para } \\
\text { o projeto de Ensino de Matemática e Instrumento Didático pelo par } \\
\text { mais experiente. } \\
\text { Sessão reflexiva: projeto de Ensino de Matemática e Instrumento } \\
\text { Didático. }\end{array}$ \\
\hline 19 & $24 / 02 / 2017$ & $\begin{array}{l}\text { Encerramento da Disciplina de Estágio Supervisionado II: Palestra } \\
\text { do Prof. Dr. José Ricardo Mafra sobre a temática: "Formação de } \\
\text { Professores de Matemática e o Estágio Supervisionado" e última } \\
\text { Sessão Reflexiva. }\end{array}$ \\
\hline
\end{tabular}

Fonte: Bacury (2017) 
Dos procedimentos metodológicos adotados, selecionamos alguns contextos que explicitam quando determinada interação é colaborativa e quando se constitui um espaço de cooperação.

Os extraits apresentados são falas dos partícipes e se referem ao procedimento metodológico intitulado Palestra. Essas palestras objetivaram suprir necessidades formativas dos estudantes-partícipes concernentes aos conhecimentos necessários ao enfrentamento de desafios decorrentes das atividades de ensinar e de aprender as Matemáticas nas escolas de educação básica.

A seguir, apresentamos o quadro 3, referente às sínteses das palestras realizadas durante os encontros do GEPIMat.

\section{Quadro 3}

\section{Palestrantes e Temáticas}

\begin{tabular}{|l|l|}
\hline \multicolumn{1}{|c|}{ Palestrantes } & \multicolumn{1}{c|}{ Temáticas } \\
\hline Prof. Me. Jorge Menezes Rodrigues & $\begin{array}{l}\text { A Matemática e os portadores de necessidades } \\
\text { educacionais especiais. }\end{array}$ \\
\hline Prof. Me. Ademar Vieira & $\begin{array}{l}\text { Experiências e vivências com o doutorado na } \\
\text { Universidade de Aveiro - Portugal. }\end{array}$ \\
\hline Prof. Me. Domingos Anselmo & $\begin{array}{l}\text { A relação entre a Matemática acadêmica e a } \\
\text { Matemática escolar nas práticas docentes da } \\
\text { Educação Básicas. }\end{array}$ \\
\hline Prof. a. Dr. ${ }^{a}$ Elisângela Melo & $\begin{array}{l}\text { Formação de Professores de Matemática na pers- } \\
\text { pectiva da Etnomatemática e Comunidades de } \\
\text { Prática. }\end{array}$ \\
\hline Prof. Dr. José Ricardo Mafra & $\begin{array}{l}\text { Formação de Professores de Matemática e o } \\
\text { Estágio Supervisionado. }\end{array}$ \\
\hline
\end{tabular}

Fonte: Adaptado de Bacury (2017).

A realização dessas palestras subsidiou as discussões e reflexões dos partícipes quanto a formação e atuação do professor de Matemática frente aos desafios dos processos de ensino e de aprendizagem das Matemáticas em sala de aula, bem como das pesquisas desenvolvidas sobre formação de professor com desdobramento em outras atividades desenvolvidas no grupo.

A discussão que segue é referendada em extraits da interação discursiva vivenciada na sessão reflexiva sobre "Projeto de Ensino de Matemática e Instrumento Didático" no contexto do processo investigativo/formativo. 
A elaboração dos projetos de ensino de Matemática pelos partícipes foi proposta a partir da constatação, evidenciada por Cunha (201 1), que muitas vezes essa atividade não é executada de forma satisfatória, particularmente, nas unidades escolares.

A decisão para elaborar os projetos ocorreu em três fases. Inicialmente, foram sugeridos pelo pesquisador oito temas segundo as tendências da Educação Matemática, como apresenta no quadro 4, a seguir.

\section{Quadro 4}

\section{Temas sugeridos}

\begin{tabular}{|c|}
\hline Temas \\
\hline Material Concreto \\
Jogos Matemáticos \\
Tratamento de Informação \\
Resolução de Problemas \\
História da Matemática \\
Etnomatemática \\
Novas Tecnologias \\
Modelagem Matemática \\
\hline
\end{tabular}

Fonte: Elaborado pelos autores.

Cinco temas foram escolhidos a partir do interesse dos estudantes-partícipes, a saber: Material Concreto, Jogos Matemáticos, Resolução de Problemas, História da Matemática e Novas Tecnologias. Por último, foi realizado um sorteio para organizar os grupos pelos temas escolhidos.

Desse modo, foram elaborados cinco projetos:

- $O$ aprendizado dos números irracionais em uma breve história;

- Educação Matemática financeira;

- Os jogos como ferramenta de aprendizagem do sistema métrico decimal;

- $\bigcirc$ uso do material concreto no ensino e aprendizagem de frações;

- Novas tecnologias para a construção do Teorema de Pitágoras.

Os projetos foram planejados para o ensino e a aprendizagem de estudantes do ensino fundamental II, do ensino médio e da Educação especial. 
Nessa direção, foram constituídos momentos de análise e de discussão dessas produções acadêmicas. Recorremos às Sessões Reflexivas com base nas ferramentas para a recolhas dessas informações.

Essas sessões tiveram a duração de, em média, seis horas, durante os encontros do GEPIMat na UFAM, registrado em audiovisual. Os registros das interações orais foram transcritos pelo pesquisador da forma como os partícipes emitiram seus enunciados ${ }^{2}$.

Para Bakhtin (2003), enunciado é ato de exprimir, transmitir pensamentos, sentimentos etc. em palavras.

Passaremos, a seguir, às análises dos momentos interativos vivenciados na Sessão Reflexiva, anteriormente mencionada. Como no caso das palestras, destacado pelo partícipe Castro:

Com a palestra sobre educação especial, aprendemos muito. Pois é um campo bastante interessante, a graduação não nos proporciona conhecer os tipos de alunos com necessidades especiais. Durante a palestra, conseguimos ter uma noção de que existem, sim, alunos com necessidades especiais e que eles também se encontram inseridos nas escolas inclusivas (CASTRO, 2017).

Como podemos observar, as palestras se constituíram em uma contribuição para ampliar o conhecimento acerca da realidade contextual do espaço escolar, evidente na fala de Castro (Sessão Reflexiva, 2017), quando afirma que "[...] a graduação não nos proporciona conhecer os tipos de alunos com necessidades especiais [...]". E acrescenta: "Durante a palestra conseguimos ter uma noção de que existem, sim, alunos com necessidades especiais [...]".

O fato também foi destacado por Veigas ao argumentar que "A palestra realizada pelo professor convidado nos ensinou muito sobre os portadores de necessidades especiais que precisam de profissionais capacitados para ajudá-los no seu desenvolvimento educacional $[\ldots]^{\prime \prime}$.

A palestra realizada pelo professor convidado nos ensinou muito sobre os portadores de necessidades especiais que precisam de profissionais capacitados para ajudá-los no seu desenvolvimento educacional, falou sobre a escola onde ele trabalha, mostrando imagens dela e de alguns objetos adaptados para essas crianças, alguns foram criados por ele. Teve uma importância muito grande para mim porque podemos sentir que há outras pessoas especiais 
que também são seres humanos necessitando de ensinamentos, ainda que não tenham escolas suficientes no nosso estado. São necessários profissionais que possam trabalhar com essas crianças [...] (VIEGAS, 2017).

A partir das falas de Viegas e Castro, o processo instaurado se situa num contexto de cooperação, uma vez que se configura como uma contribuição, à medida que as informações transmitidas pelo palestrante possibilitaram aos partícipes ter uma "noção", como sinalizou anteriormente Castro, de uma realidade que eles desconheciam.

No caso destacado, não se evidencia nenhuma intenção do palestrante em propiciar uma reflexão crítica sobre a problemática em pauta ou implicar-se de forma volitiva e consciente no processo formativo dos partícipes.

Como contraponto, passaremos a discutir situações que denotam interações, permitindo-nos detectar contextos colaborativos.

Nesse sentido, retomaremos a discussão que se efetivou na Sessão Reflexiva. No decorrer das ações de reflexão, instaurou-se uma situação de 14 discursiva, a partir da colocação do partícipe Alves sobre a elaboração dos projetos de ensino de Matemática.

Esse nosso trabalho aí quase não fazíamos porque com muitas pessoas parece que fica mais difícil, cada um tem uma ideia [...] uns aceitam, outros não, tira isso e coloca aquilo. [...] $\bigcirc$ ser humano é triste em não querer abrir mão de suas ideias [...] no trabalho colaborativo, você tem que abrir mão de algumas ideias. Então se torna mais difícil! [...] (ALVES, 2016).

A argumentação de Alves sobre a dificuldade de elaborar o projeto de ensino de Matemática num processo colaborativo se origina no fato das pessoas arraigarem-se a suas ideias, preocupando-se mais com seus posicionamentos do que considerar a relevância dos argumentos para a consecução dos objetivos propostos. Por esse motivo, afirmou: "[...] no trabalho colaborativo você tem que abrir mão de algumas ideias. Então se torna mais difícil [...]". $\bigcirc$ argumento de Alves possibilitou ao grupo refletir sobre a contribuição do trabalho colaborativo no processo de formação profissional. A interação dialógica instaurada permite que outros partícipes, a partir do questionamento do pesquisador, argumentem sobre a discussão em pauta: Questionamento do 
Pesquisador Alves argumentou que o trabalho colaborativo é difícil porque as pessoas não abrem mão de suas ideias. Vocês concordam?

É difícil, pois o que penso não é a mesma coisa que o outro vai pensar. $\bigcirc$ que acho não é a mesma coisa que ele vai achar [...] (PEQUENO, 2016).

$[\ldots]$

Para mim, o trabalho colaborativo ocorreu por meio da interação com o grupo envolvido de forma que todos se beneficiassem com a pesquisa e, para isso, houve o compartilhamento de conhecimento dentre os participes do grupo (MOURAJUNIOR, 2016).

$[\ldots]$

Achei interessante (referindo-se ao trabalho colaborativo) (CAMPOS, 2016).

$[\ldots]$

(Questionamento do pesquisador: Por que Campos?)

Achei interessante essa forma de trabalhar, até porque isso nos beneficia bastante, pois, no mercado de trabalho, frequentemente, estaremos em equipe. É muito bom compartilhar experiências, pois isso só agrega ao conhecimento de todos (CAMPOS, 2016).

Nesse contexto interativo, instaurou-se um processo colaborativo à medida que possibilitou condições igualitárias aos envolvidos se sentirem autorizados a expor suas ideias e opiniões, assim como a percepção da necessidade de que todos participassem e tivessem espaço assegurado para emitir suas posições, concordar ou não com as ideias expostas.

Fica evidente a intencionalidade do pesquisador /par mais experiente) de oportunizar vez e voz a todos, uma vez que, retomava e questionava os argumentos, no sentido de oferecer aos interlocutores a possibilidade de exporem seus pontos de vista e se sentirem parceiros na interpretação e (re) elaboração de saberes. Como destaca Campos (2016): "É muito bom compartilhar experiências, pois isso só agrega ao conhecimento de todos".

$\bigcirc$ contexto colaborativo contribuiu, também, para a expansão de sentidos, inicialmente apresentado por Pequeno, no que se refere à dificuldade de trabalhar em colaboração, como mostra o seguinte extrait, em que o compartithamento tornou a (re)significação viável. 
Mesmo com algumas ideias adversas, cada um tentou ajudar, completava [...]. Isso abria oportunidades, dava chance ao outro de se manifestar. Acho que isso é trabalhar colaborativamente, dar vez e voz [...] é isso que tiro de compreensão: saber escutar, saber o momento de falar, o momento de opinar (PEQUENO, 2016).

Embora a discussão aqui apresentada seja sucinta, é possivel perceber que instaurar a colaboração crítico-reflexiva nos processos formativos implica interações em que o discurso de uns abre espaço para que outros expressem suas ideias, mesmo que divergentes, elaborando e (re) elaborando significados via contribuição mútua, promovendo a formação de indivíduos que contribuam com os demais de modo reciprocamente enriquecedor, com os conhecimentos produzidos pela relação mantida uns com os outros.

A argumentação se efetivou em termos de negociação onde todos tiveram a mesma oportunidade de opinar sobre a temática, foco do diálogo, isto é, a dificuldade de trabalhar colaborativamente. Esse fato, no nosso entender, tornou a ação formativa propiciadora de novas possibilidades de agir dos envolvidos nessa interação, conforme as falas expressas nos seguintes extraits.

Mas, dessa vez, foi diferente, tive um grande avanço na comunicação[...]. A insegurança de falar correto, ao dar uma aula, foi preenchida por novas formas de expressar e explicar determinados assuntos. Essa maneira, de abordar [...] é o início de uma nova fase para nós, alunos da graduação, que buscamos a melhor preparação como futuros professores (IBERNON, 2016).

Sei que essa contribuição mútua vai além do nível de sala de aula (PEQUENO, 2016).

Outro aspecto a destacar é a função exercida pelos questionamentos. Não é qualquer tipo de questão que propicia a interação colaborativa crítico-reflexiva. É fundamental que as questões postas não tenham a conotação de autoritarismo, ou imposição, ou demonstração de poder.

[...] o questionamento, sozinho, [...] não é suficiente para promover a colaboração crítica, é necessário que as pessoas se engajem na relação com outras pessoas, produzindo objeto comum de compreensão e o agir transformador (IBIAPINA; MAGALHÃES, 2012, p. 410$)$. 
Contudo, nos processos formativos centrados na pesquisa, as interações nem sempre se caracterizam como colaborativas crítico-reflexivas. Muitas vezes, as situações emergentes não são questionadas, perdendo-se a chance de compartilhamento das vivências e experiências, assim como a expansão das interações.

Desse modo, permeia ações formativas de caráter predominantemente cooperativo. Isso não significa que essas ações não tenham sua pertinência, ao contrário, em processos formativos que objetivam criar espaços de colaboração e reflexão crítica as interfaces entre colaborar e cooperar poderão produzir uma contribuição efetiva na formação profissional dos envolvidos.

No caso da pesquisa que consideramos como referência, isso possibilito aos partícipes superar lacunas advindas do processo formativo que estavam vivenciando. Evidência disso é o fato dos partícipes destacarem a importância dessas contribuições nos momentos de reflexão.

A participação do professor Jorge com sua palestra sobre Educação especial me motivou ainda mais a fazer parte de educadores nessa área. Realmente tive noção de como seria trabalhar com crianças cegas, autistas, entre outras, porque durante o curso não somos preparados para trabalhar com crianças que necessitam de uma educação especial, uma atenção e não exclusão [...] (ALVES, 2017).

$[\ldots]$

O professor Santos ensinou um pouco sobre sua vivência em outro país, mas, o que foi importante foi a sua colaboração como pedagogo, que nos ensinou a entender os nossos futuros alunos, como devemos agir diante de algum fato que ocorrer. Ensinou coisas que eu nem imaginava que pudessem acontecer na academia e na vida, suas palavras me motivaram a querer buscar mais [...]. (VIEGAS, 2017a).

$[\ldots]$

As palestras dos professores tiveram um impacto e tanto, principalmente o professor que falou sobre as pessoas com necessidades especiais (HIPÓLITO, 2017).

Esses enunciados refletem as condições específicas do contexto em que as interações se produziram. Nessa ocasião, os participes vivenciaram momentos de expansão da capacidade reflexiva, da crítica e da compreensão, 
tornando-se capazes de fazer a distinção do que é essencial e o que é secundário para a viabilização de seus propósitos, como destaca Viegas (2017a): "O professor Vieira ensinou um pouco sobre sua vivência em outro país, mas o que foi importante foi a sua colaboração como pedagogo que nos ensinou a entender os nossos futuros alunos $[\ldots]^{\prime \prime}$.

Vale salientar que, nas duas situações interativas (cooperação e colaboração), nos encontramos diante da modalidade discursiva de comunicação. Nessa modalidade do discurso ocorre o que Bakhtin (2003) denomina de "posição responsiva", isto é, não existe passividade na interação discursiva, os envolvidos nessa interação podem intervir oralmente ou de forma silenciosa.

[...] essa posição responsiva do ouvinte se forma ao longo de todo processo de audição e compreensão desde o seu início, às vezes literalmente a partir da primeira palavra do falante. Toda compreensão da fala viva, do enunciado vivo é de natureza ativamente responsiva (embora o grau desse ativismo seja bastante diverso). Toda compreensão é prenhe de resposta, e nessa ou naquela forma [...] o ouvinte torna-se falante (BAKHTIN, 2003, p. 271).

E o autor acrescenta:

É claro que nem sempre ocorre imediatamente [...], pode permanecer de quando em quando como compreensão responsiva silenciosa [...], mas isto, por assim dizer, é uma compreensão responsiva de feito retardado: cedo ou tarde, o que foi ouvido e ativamente entendido responde nos discursos subsequentes ou no comportamento do ouvinte (BAKHTIN, 2003, p. 271).

No caso aqui analisado, a compreensão responsiva que foi silenciada na situação de cooperação torna-se ativa quando se instaura o processo de colaboração.

A teoria do discurso de Bakhtin (2003) com seus componentes o enunciado, a alternância e a conclusibilidade, nos possibilita estabelecer aspectos em que a cooperação e a colaboração crítico-reflexiva se assemelham e se diferenciam, assim como, a viabilidade de suas interconexões. 


\section{O que o espelho não revela}

Colaboração e cooperação são processos que apesar de distintos e até mesmo contrários apresentam propriedades possiveis de ser relacionadas. Essas afinidades tornam-se evidentes quando essas propriedades são apreendidas.

No caso em discussão, tanto o ato de colaborar quanto o de cooperar têm como componente constitutivo a atividade discursiva. Esse elemento de conformidade faz com que a cooperação e a colaboração se assemelhem, chegando, muitas vezes, a se confundir e serem consideradas sinônimos.

Compreendemos que esse fator unificador não conduz simplesmente substituir, mecanicamente, um processo pelo outro, mas, ao contrário, torna esses processos interpenetráveis, criando áreas de conexão, mantendo, ao mesmo tempo, suas especificidades. Como esclarece Bakhtin (2003), a atividade discursiva se diversifica segundo seu campo de ação, ou seja, o contexto no qual se efetiva.

Como já dissemos anteriormente, a colaboração implica a inclusão do outro, de forma consciente e volitiva, como parceiro interlocutor na posição responsiva ativa de concordar, discordar, agir, dentre outros, o que não é, necessariamente, a finalidade da cooperação. Contudo, como afirma, Bakhtin:

[...] todo falante é por si mesmo um respondente em maior ou menor grau: porque ele não é o primeiro falante, o primeiro a ter violado o eterno silêncio do universo, e pressupõe não só a existência do sistema da língua que usa, mas também de alguns enunciados antecedentes - dos seus e alheios - com os quais o sev enunciado entra nessas ou naquelas relações (baseia-se neles, polemiza com eles, simplesmente os pressupõe já conhecidos do ouvinte). Cada enunciado é um elo na corrente complexamente organizada de outros enunciados (BAKHTIN, 2003, p. 272).

Nessa direção, fica evidente que cooperar e colaborar não são atividades impenetráveis. Dado o elemento que as tornam similares - a comunicação discursiva - elas mantêm interfaces nos contextos formativos relacionados aos processos de pesquisas em que a cooperação tem um papel complementar significativo na formação dos envolvidos nesse processo. 
Porém, a criação de contextos colaborativos faz surgir a possibilidade de se operarem mudanças qualitativas no que se refere à atividade discursiva dos partícipes expressas nas propriedades essenciais e distintivas do discurso - o sentido dos enunciados e a posição ativa dos atores. Segundo Ferreira (2012, p. 392), a pesquisa colaborativa "[...] é uma abordagem em que os objetivos da pesquisa e da formação encontram-se imbricados, permitindo a inter-relação entre os atores do processo [...]". $\bigcirc$ destaque atribuído à participação ativa dos implicados no processo de formação foi imprescindível para essas mudanças se efetivarem, mesmo que não tenham ocorrido em toda sua extensão.

A advertência de Eagleton (2012, p. 60) de que "É preciso haver um meio de escanear ou radiografar o presente que mostre determinado futuro como um potencial dentro dele [...]" nos faz refletir sobre o significado de mudanças que ocorrem em contextos inovadores tais como o aqui analisado.

Em nosso entender, elas representam esse potencial de possibilidades, de efetivarem-se trabalhos educativos qualitativamente diferenciados, procurando sempre olhar além das aparências superficiais e enganadoras

20 constitutivas do nosso entorno. É fundamental reconhecermos a importância de sabermos distinguir a aparência da essência e descobrir o que se esconde por trás dessa confusão de aparências superficiais e em geral mistificadoras.

\section{Fragmentos do espelho}

Ao abordarmos nesse texto a questão das relações entre cooperar e colaborar, não nos propomos a discuti-la em toda sua complexidade. Nossa intenção foi de analisar apenas aspectos dessas relações que nos parecem de importância substancial.

Para nós, importa não só constatar que elas ocorrem, como fica demonstrado nos extraits do processo vivenciado no contexto formativo centrado em Práticas Investigativas em Educação Matemática (BACURY, 2017), mas, principalmente, compreender com precisão o porquê delas se efetivarem.

Nessa perspectiva, procuramos evidenciar o modo interno de estruturação de cada uma dessas modalidades de ação (cooperar/colaborar), como seus elementos se organizam, se relacionam e se conectam, propiciando a unidade na diversidade das propriedades que as constitui. Ou seja, a atividade 
discursiva consubstanciada nos seus enunciados, assim como sua exteriorização na relação entre generalidade, particularidade e singularidade, mantendo a unidade sem perder as suas formas específicas na modalidade concreta de suas manifestações empíricas.

É verdade que os estudiosos procuraram sempre destacar as diferenças existentes entre elas, sem se preocuparem com suas semelhanças. No entanto, para termos a dimensão exata de um fenômeno, é necessário o exame de suas relações internas e externas. A semelhança unifica o que as diferenças separam, determinando as singularidades.

Não podemos deixar de salientar que são as propriedades distintivas que favorecem as mudanças, tanto quantitativas quanto qualitativas, como demonstra os enunciados analisados. Convém recordar que essas mudanças não se processaram extensivamente. Todos nós sabemos o quanto é desafiante propô-las e criar condições que as viabilizem. A posição mais cômoda é permanecermos na nossa "zona de conforto".

Todavia, estudos como os de Silva (2006) corroboram a importância da teoria do discurso na constituição dos enunciados no movimento da construção, desconstrução e reconstrução das inferências sobre si mesmo, o outro e seu entorno, possibilitando a compreensão das ambivalências, das alteridades e das contradições implicadas em processos que envolvem interações múltiplas.

Ibiapina e Magalhães (2012) apresentam algumas situações que terão que enfrentar aqueles que se aventuram a inovar, em particular, em promover a colaboração crítico-reflexiva no âmbito das instituições educacionais (escolares ou universitárias).

[...] em geral, organizações colaborativo-argumentativas não são valorizadas, quer pela convicção de que questionar o outro com base em argumentos concretos não é desejável; quer pela compreensão de que cada professor deve organizar suas ações com base em suas compreensões como sujeitos individuais e não com parceiros que juntos discutem o coletivo da escola, seus problemas e necessidades e compartilham decisões teóricas e práticas na organização de modos de agir. (IBIAPINA; MAGALHÃES, 2012, p. 415). 
Ainda mais, no âmbito geral da nossa sociedade, as condições estão cada vez mais adversas. Urge hoje, mais que antes, termos coragem, ousadia e correr riscos para enfrentar e reverter a situação em que nos encontramos.

Gostaríamos de acrescentar que essas considerações têm o propósito de destacar, por um lado, aspectos nem sempre considerados nos processos formativos mediados pela pesquisa, isto é, as inter-relações entre cooperar e colaborar e sua contribuição na qualificação desses processos. Por outro, esclarecer elementos relevantes que possam tornar mais evidentes a sua viabilidade em contextos mais abrangentes. É fundamental lembrar que é na unidade dialética entre realidade e possibilidade que se produzem as causas, as casualidades, as contradições e as condições dessas possibilidades se tornarem realidade.

\section{Nota}

1 Disponível em: http://dgp.cnpq.br/dgp/espelhogrupo/320244.

222 Para Bakhtin (2003), enunciado é ato de exprimir, transmitir pensamentos, sentimentos, etc. em palavras

\section{Referências}

ALARCÃO, Izabel. Professores reflexivos em uma escola reflexiva. São Paulo: Cortez, 2011 .

ALVES. Sessão reflexiva. (Amazonas), Manaus, 16 fev. 2016.

ALVES. Sessão reflexiva. (Amazonas), Manaus, 24 fev. 2017.

BOAVIDA, Ana Maria; PONTE, João Pedro da. Investigação colaborativa: potencialidades e problemas. In: GRUPO de Trabalho sobre Investigação (GTI). Refletir e investigar sobre a prática profissional. Lisboa: APM, 2002. Disponível em: http://repositorio.ul.pt/ bitstream/10451/4069/1/02-Boavida-Ponte\%20\%28GT1\%29.pdf. Acesso em: 5 set. 2017.

BACURY, Gerson Ribeiro. Práticas investigativas na formação de futuros professores de matemática. 188f. Tese (Doutorado em Educação em Ciências) - Programa de PósGraduação em Educação em Ciências, Universidade Federal do Pará, Belém, 2017. 
BAKHTIN, Mikhail. Estética da criação verbal. Tradução Paulo Bezerra. 4. ed. São Paulo: Martins Fontes, 2003

CAMPOS. Sessão reflexiva. (Amazonas), Manaus, 16 fev. 2016.

CASTRO. Sessão reflexiva. (Amazonas), MANAUS, 24 fev. 2017.

CELANI, Maria Antonieta Alba. Um programa de formação continua. In: CELANI, Maria Antonieta Alba (Org.). Professores e formadores em mudança: um processo de reflexão e formação da prática docente. Campinas: Mercado das Letras, 2003.

CUNHA, Lúcia de Fátima. Planejamento!? Que é isso? In: BALDI, Elena Mabel Brutten; PIRES, Gláucia do Nascimento da Luz; FRERREIRA, Maria Salonilde (Org.). Políticas educacionais e práticas educativas. Natal: EDUFRN, 2011.

EAGLETON, Terry. Marx estava certo. Tradução Regina Lyra. Rio de Janeiro: Nova Fronteira, 2012.

FERREIRA, Maria Salonilde. A abordagem colaborativa: uma articulação entre pesquisa e formação. In: SAMPAIO, Marisa Narcizo; SILVA, Rosália de Fátima e (Org.). Saberes e práticas de docência. Campinas: Mercado de letras, 2012.

FERREIRA, Maria Salonilde; IBIAPINA, Ivana Maria Lopes de Melo. A Pesquisa colaborativa como espaço formativo. In: MAGALHÃES, Maria Cecília Camargo; FIDALGO, Suely Salles (Org.). Questões de método e de linguagem na formação docente. Campinas: Mercado das Letras, 2011.

HIPÓlITO. Sessão reflexiva. (Amazonas), Manaus, 24 fev. 2017.

IBERON. Sessão reflexiva. (Amazonas), Manaus, 16 fev. 2016.

IBIAPINA, Ivana Maria Lopes de Melo. Pesquisa colaborativa: investigação, formação e produção de conhecimento. Brasília: Liber livro, 2008.

IBIAPINA, Ivana Maria Lopes de Melo. Pesquisar e formar colaborativamente: desafios e perspectivas. In: BALDI, Elena Mabel Brütten; FERREIRA, Maria Salonilde; PAIVA, Marlúcia (Org.). Epistemologia das ciências da educação. Natal: EDUFRN, 2009.

IBIAPINA, Ivana Maria Lopes de Melo; MAGALHÃES, Maria Cecília Camargo. Colaborar na pesquisa e na formação docente: o que significa? Como agir? In. SAMPAIO, Marisa Narcizo; SILVA, Rosália de Fátima e (Org.). Saberes e práticas de docência. Campinas: Mercado de letras, 2012.

JOHN-STEINER, Vera. Creative Collaboration. Nova York: Oxford Press, 2000. 
Colaborar ou cooperar? diz espelho meu!

MAGALHÃES, Maria Cecília Camargo. Sessões Reflexivas como uma ferramenta aos professores para a compreensão crítica das ações da sala de aula. In: CONGRESSO DA SOCIEDADE INTERNACIONAL PARA A PESQUISA CULTURAL E TEORIA DA ATIVIDADE, 5., 2002. Amsterdan. Anais [...]. Amsterdan: Vrije Universities, 2002.

MAGALHÃES, Maria Cecília Camargo. A linguagem na formação de professores reflexivos e críticos. In: MAGALHÃES, Maria Cecília Camargo (Org.). A formação do professor como um profissional critico: linguagem e reflexão. Campinas: Mercado das Letras, 2004.

MAGALHÃES, Maria Cecília Camargo. Prefácio. In: MAGAlHÃES, Maria Cecília Camargo (Org.). Formação crítica de educadores: questões fundamentais. Taubaté: Cabral Editora/ Livraria Universitária, 2008.

MAGALHÃES, Maria Cecília Camargo. Pesquisa crítica de colaboração em projetos de formação contínua em contextos escolares: colaboração na pesquisa e na ação. In: BALDI, Elena Mabel Brütten; FERREIRA, Maria Salonilde; PAIVA, Marlúcia (Org.). Epistemologia das ciências da educação. Natal: EDUFRN, 2009.

MAGALHÃES, Maria Cecília Camargo. $\bigcirc$ método para Vygotsky: A zona proximal de desenvolvimento como zona de colaboração e criticidades criativas. In: DAMIANOVIC, 24 Maria Cristina; SZUNDY, Paula Tatianne Carrera; HAWI, MONA MOHAMAD; SHETTINI, ROSEMARY HOHLENWZ (Orgs.) Vygotsky: uma (re) visita no século XXI. São Paulo: Andross, 2009.

MOURA JUNIOR. Sessão reflexiva. (Amazonas), Manaus, 24 fev. 2017.

OLIVEIRA, Raquel Gomes de. Estágio supervisionado: horas de parceria escola-universidade. Jundiaí: Paco Editorial, 2011.

PEQUENO. Sessão reflexiva. (Amazonas), Manaus, 16 fev. 2016$).$

SEIXAS, Raul. Todo mundo explica. Mata virgem. São Paulo: WEA Discos, 1979.

SILVA, Rosália de Fátima. Compreender a entrevista compreensiva. Revista Educação em Questão, Natal, v. 26, n. 1 p. 31 - 50, maio/ago. 2006.

VIEGA. Interação dialogada. (Amazonas), Manaus, 24 fev. 2017.

VIEGAS. Sessão reflexiva. 2017a. (Amazonas), Manaus, 24 fev. 2017.

Prof. Dr. Gerson Ribeiro Bacury Universidade Federal do Amazonas (Brasil) Departamento de Educação Escolar Indígena 
Grupo de Estudos e Pesquisas de Práticas Investigativas em Educação Matemática (GEPIMat/CNPq) ORCID iD: https://orcid.org/0000-0002-1 160-3187 E-mail: gersonbacury@gmail.com

Profa. Dra. Maria Salonilde Ferreira Universidade Federal do Rio Grande do Norte (Natal) Grupo de Estudos e Pesquisa Docênciae Aprendizagem(DOAPRE) ORCID iD: https://orcid.org/0000-0002-3037-755X E-mail: olaspraia2@gmail.com Recebido 29 jul. 2019 Aceito 15 ago. 2019 